\title{
Paleoclimatic implications of an 850-year oxygen-isotope record from the northern Tibetan Plateau
}

\author{
Jonathan A. Holmes, ${ }^{1}$ Jiawu Zhang, ${ }^{2}$ Fahu Chen, ${ }^{2}$ and Mingrui Qiang ${ }^{2}$ \\ Received 2 October 2007; revised 6 November 2007; accepted 13 November 2007; published 11 December 2007.
}

[1] Oxygen-isotope records from the sediments of hydrologically-closed lakes are commonly interpreted in terms of changing effective precipitation. We compare an 850-year-long oxygen-isotope record derived from ostracode carbonate from the sediments of Sugan Lake, in the northern Tibetan Plateau, with tree-ring and ice core evidence for changing temperature, precipitation and isotopic composition of the lake's inflow. Taking into account all of these independent records, we show that variations in the carbonate $\delta^{18} \mathrm{O}$ values could not have been the result of varying effective precipitation alone: changes in water temperature and in the $\delta^{18} \mathrm{O}$ of source waters also played a significant role. Where independent records of temperature, precipitation or the isotopic composition of input waters are unavailable, care should be taken to avoid simplistic interpretations of carbonate stable isotope records, as these may contribute to incorrect paleoclimatic reconstructions. Citation: Holmes, J. A., J. Zhang, F. Chen, and M. Qiang (2007), Paleoclimatic implications of an 850-year oxygen-isotope record from the northern Tibetan Plateau, Geophys. Res. Lett., 34, L23403, doi:10.1029/2007GL032228.

\section{Introduction}

[2] The Asian monsoon impacts around half the world's population. Correctly interpreted proxy records of past monsoon variability from the pre-instrumental period are vital for our understanding of the sensitivity of the monsoon to external forcing and to help predict its future behavior. Previous studies have shown that the strength of Asian summer monsoon circulation has gradually decreased since the early Holocene in response to orbitally-forced reduction in summer insolation and that abrupt changes in monsoon intensity superimposed on this trend appear to be linked to $\mathrm{N}$. Atlantic cooling cycles and, ultimately, to solar variability [e.g., Wang et al., 2005].

[3] Lake-sediment sequences may provide excellent records of climate change in arid regions. In hydrologicallyclosed lakes, changes in the volume, chemistry, and isotopic composition of lake water commonly result from variations in effective moisture. Oxygen isotopes, in particular, are especially sensitive to changes in the local hydrological cycle. When effective precipitation decreases, lake water becomes enriched in the heavy isotope ${ }^{18} \mathrm{O}$ as a result of

\footnotetext{
${ }^{1}$ Environmental Change Research Centre, University College London, London, UK.

${ }^{2}$ Center for Arid Environment and Paleoclimate Research (CAEP), MOE Key Laboratory of West China's Environmental System, Lanzhou University, Lanzhou, China.
}

Copyright 2007 by the American Geophysical Union. 0094-8276/07/2007GL032228 preferential evaporative loss of water containing ${ }^{16} \mathrm{O}$, whereas during wetter periods it becomes relatively enriched in ${ }^{16} \mathrm{O}$. Temporal changes in the ${ }^{18} \mathrm{O} /{ }^{16} \mathrm{O}$ ratio of lake water may register in the lake's sediment record, especially in carbonates. Despite multiple controls on the oxygen-isotope ratios of carbonates, temporal variations in ${ }^{18} \mathrm{O} /{ }^{16} \mathrm{O}$ values in hydrologically-closed lakes are usually interpreted in terms of changing effective moisture [e.g., Hodell et al., 1995]. In this paper, we evaluate multiple controls on the lake-sediment oxygen-isotope record from Sugan Lake, on the northern Tibetan Plateau, using independent records of temperature and precipitation amount, both derived from published tree-ring sequences, and of the oxygen-isotope composition of input water, derived from the nearby Dunde Ice Cap. The northern margin of the Tibetan Plateau lies close to the present limit of East Asian summer monsoon precipitation and is therefore sensitive to temporal changes in monsoon circulation. Oxygen-isotope values of carbonates from Tibetan Plateau lakes have broadly increased during the Holocene, in response to reduced effective precipitation and resulting evaporative enrichment [e.g., Lister et al., 1991] accompanying the waning monsoon.

[4] The past millennium has been a time of marked climatic variability and it includes the so-called Medieval Warm Period (MWP) and Little Ice Age (LIA). However, the nature, timing, and spatial variability of climatic change over the Tibetan Plateau for the past 1000 years is poorly constrained: for example, ice cores [e.g., Thompson et al., 1989] and tree-ring sequences [e.g., Liu et al., 2005] reveal marked temperature variability during each of these climatic episodes. Yang et al. [2002] suggest that the MWP occurred on the Plateau between about 1000 and $1300 \mathrm{AD}$ followed by the LIA from about 1350-1900 AD and then rapid 20th century warming. Evidence for change in precipitation is more ambiguous. Marine records suggest an intensification of the East Asian summer monsoons during the MWP followed by weakening during the LIA [Wang et al., 1999]. Terrestrial evidence from Asia is less clear, however, and although ice-core accumulation and tree-ring records suggest that the frequency and intensity of droughts and/or reduced monsoon activity has been greater during the LIA interval [e.g., Wang et al., 2005; Davis et al., 2005; Shao et al., 2005], the LIA was not simply a period of prolonged drought. Moreover, Chen et al. [2006] have presented paleolimnological evidence for a wetter LIA in the area to the northwest of the Tibetan Plateau, which implies that spatial variability in past climate across western China may have been marked. Clearly, additional paleoclimate records are required from this vast area if the impacts of recent monsoon variability are to be properly understood. 


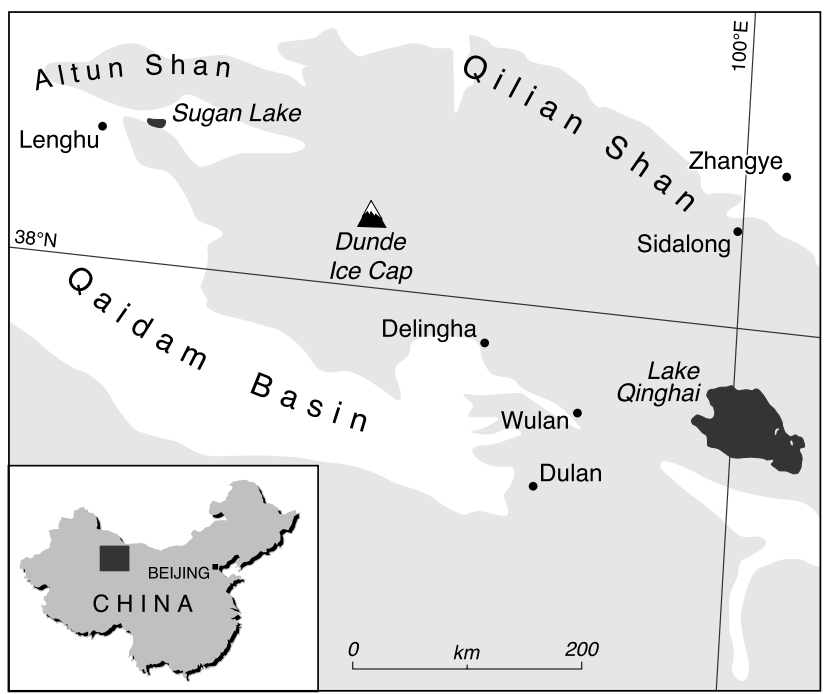

Figure 1. Location of study area, showing Sugan Lake and other sites discussed in the text.

[5] Lake records can potentially preserve lower-frequency variability than tree ring records and are more ubiquitous than ice cores. However, correct interpretation of proxy records is vital if further progress is to be made into the understanding of recent climatic variability over the Tibetan Plateau. Sugan Lake lies in a hydrologically closed basin on the northern margin of the Tibetan Plateau (Figure 1). In such a climatic and hydrological setting, the carbonate oxygen-isotope record would classically be used as a proxy for effective precipitation. However, we show here that factors other than effective precipitation contributed to the oxygen-isotope record from Sugan Lake, and discuss the implications of this finding for our understanding of the climate history of the region.

\section{Study Site}

[6] Sugan Lake $\left(38^{\circ} 51^{\prime} \mathrm{N}\right.$; $93^{\circ} 54^{\prime} \mathrm{E}$; area $104 \mathrm{~km}^{2}$, water level $2793 \mathrm{~m}$ a.s.1.) is shallow (mean depth $2.8 \mathrm{~m}$, maximum depth $6 \mathrm{~m}$ ), saline, and alkaline (mean salinity $\sim 32 \mathrm{~g} \mathrm{l}^{-1}$, $\mathrm{pH}=8.5$ ). Most of the basin lies between 2800 and $3200 \mathrm{~m}$ a.s.1., with surrounding peaks rising to $>5000 \mathrm{~m}$ a.s.1. The catchment is arid (annual precipitation $15.8 \mathrm{~mm}$, potential evaporation $2900 \mathrm{~mm}$ ) with a mean annual temperature of $2.8^{\circ} \mathrm{C}$ (data from China Meteorological Administration). The lake is fed indirectly by two rivers, which originate in the wetter mountains to its southeast, disappear into surficial gravels in the piedmont area and then either re-emerge as springs and small streams that subsequently flow into the lake, or contribute to direct shallow groundwater inflow along the lake margin.

[7] Measurements of the $\delta^{18} \mathrm{O}$ values of precipitation $\left(\delta^{18} \mathrm{O}_{\mathrm{p}}\right)$ in the lake's catchment have not been made. However, the oxygen-isotope composition of large rivers on the Tibetan Plateau provides a record of 'average' $\delta^{18} \mathrm{O}_{\mathrm{p}}$ values within their catchments [Tian et al., 2001]. The $\delta^{18} \mathrm{O}$ values for rivers that feed Sugan Lake are c. $-10 \%$ (J. W. Zhang, unpublished data, 2007), consistent with measured $\delta^{18} \mathrm{O}_{\mathrm{p}}$ values of about $-8 \%$ for Delingha, which lies $330 \mathrm{~km}$ to the southeast of Sugan Lake at $2981 \mathrm{~m}$ a.s.l.
[Tian et al., 2003], and with core-top values for the Dunde Ice Cap $(-10.1 \%$ ), at $\sim 5300 \mathrm{~m}$ a.s.1. [Thompson et al., 1989]. The offset between the $\delta^{18} \mathrm{O}$ values for Sugan river water and Delingha precipitation likely arises because precipitation feeding the inflowing rivers was derived from higher altitude (up to $5000 \mathrm{~m}$ a.s.1.) than the Delingha site. Sugan Lake water currently has a mean $\delta^{18} \mathrm{O}$ value of about +4\% VSMOW (J. W. Zhang, unpublished data, 2007), reflecting strong evaporative enrichment of the input waters.

\section{Material and Methods}

[8] This study is based on the laminated ostracodebearing upper 2.19 meters of the 8.52-m-long core SG00C, recovered from $4.52 \mathrm{~m}$ water depth in the central part of the lake. On the basis of detailed mineralogical, structural and biological examinations, coupled with comparisons to ${ }^{210} \mathrm{~Pb}$ and ${ }^{137} \mathrm{Cs}$ chronologies on parallel core SG00I, the laminations were found to be annual varves [Zhou et al., 2007]. Varve counting was therefore used to develop an age model for the cores, which indicates that the section of core SG00C studied here covers the past $\sim 850$ years. Despite the annual nature of the laminae, there are several intervals in the core in which the laminae are present but unclear, potentially leading to uncertainties in the chronology. Despite this, we believe that the chronology used here is broadly correct.

[9] About $5 \mathrm{~g}$ of sediment from each contiguous $1-\mathrm{cm}$ interval of SG00C was disaggregated in distilled water and sieved through a $125 \mu \mathrm{m}$ mesh: ostracodes were picked from the oven-dried $>125 \mu \mathrm{m}$ residue. Assemblages, which were deemed in situ based on the presence of adult and juvenile valves, consisted solely of the euryhaline species Eucypris inflata. Three to four adult valves lacking visible overgrowths or signs of dissolution (under 40-60 x magnification) were brush-cleaned using deionised water, dried and combined for oxygen-isotope analyses, which were performed using a Finnigan MAT 253 mass spectrometer connected to a Kiel carbonate preparation device. Values are reported in standard delta notation relative to the VPDB standard, with a mean standard deviation of measurements of between 0.10 and $0.15 \%$.

\section{Results and Discussion}

[10] The steady-state oxygen-isotope composition of lake water is give by:

$$
\delta_{\text {lake }}=\frac{\left(\frac{\varepsilon}{h}+\delta_{a}\right)+\frac{I}{E}\left(\frac{1-h}{h}\right) \delta_{i}}{1+\frac{I}{E}\left(\frac{1-h}{h}\right)}
$$

[e.g., Kebede et al., 2002]. To model the steady-state $\delta^{18} \mathrm{O}$ value of Sugan Lake water, we used meteorological data from Lenghu (Figure 1) and water isotope data for the lake and catchment (mean annual temperature $=2.4 .{ }^{\circ} \mathrm{C}$, mean relative humidity $h=0.35$, isotopic composition of inflow $\delta^{18} \mathrm{O}_{\mathrm{i}}=-10 \%$, isotopic composition of atmospheric vapour $\delta^{18} \mathrm{O}_{\mathrm{a}}$, in isotopic equilibrium with $\delta^{18} \mathrm{O}_{\text {precipitation, }}=$ $-21.2 \%$, : total heavy isotope enrichment $\epsilon=20.1$, which comprises the temperature-dependent equilibrium fractionation factor [Majoube, 1971] and kinetic fractionation, which is controlled by humidity and given by 14.2(1-h): 
[Gonfiantini, 1986]). We assumed inflow $(\mathrm{I})=$ evaporation (E) and calculated a steady-state $\delta^{18} \mathrm{O}_{\text {lake }}$ value of $6.7 \%$, which is close to the maximum measured lake water value $(6.4 \%)$. The water isotope composition at the core site, which lies to the east of the sites of maximum ${ }^{18} \mathrm{O}$ enrichment, is rather lower $(\sim 2.7 \%)$, probably reflecting isotope 'memory' of the inflowing rivers, even though the lake is well mixed during summer. Simple calculations with the steady-state model above show that the $\delta^{18} \mathrm{O}$ value of Sugan Lake water is highly sensitive to variations in relative humidity and the isotopic composition of inflow waters, but relatively insensitive to changes in water temperature or the isotopic composition of atmospheric vapour. Variations in the balance of input to evaporative loss have a significant effect on the lake's isotope balance and changes in the lake's residence time may have played a minor role.

[11] The oxygen-isotope value of core-top $(\sim \mathrm{AD} 2000)$ ostracodes is $3.1 \%$. Observations over the past few years reveal no significant lake-level changes during this period, suggesting that the lake has been in isotopic 'steady state' over the recent past and that the measured $\delta^{18} \mathrm{O}$ value of lake water is a realistic reflection of water composition at the time when the core-top ostracode shells were secreted. Using the measured water isotope value at the core site of $2.4 \%$ and a vital offset from oxygen-isotope equilibrium in E. inflata of $+0.4 \%$ [Lister et al., 1991; Henderson, 2004], the Hays and Grossman [1991] equation yields a calcification temperature of $\sim 15^{\circ} \mathrm{C}$, consistent with summer calcification for $E$. inflata in Sugan Lake (mean summer water temperature $\approx 16^{\circ} \mathrm{C} ; \mathrm{J}$. W. Zhang, unpublished data, 2007). We therefore assume that the stratigraphic $\delta^{18} \mathrm{O}$ record from Sugan Lake is primarily a summer signal.

[12] Between AD 1150 and $1500, \delta^{18} \mathrm{O}$ values in core SG00C showed approximately bi-decadal-scale oscillations up to c. $1 \%$ amplitude superimposed on a rising and then falling trend, reaching a peak of $3.2 \%$ c. AD 1330 followed by a decline to a minimum of $1.3 \%$ around AD 1480 . The mean $\delta^{18} \mathrm{O}$ value during this interval was $\sim 2.3 \%$. Between $\mathrm{AD} 1500$ and $1560, \delta^{18} \mathrm{O}$ values became more stable although the long-term mean value was unchanged. After $\mathrm{AD} 1560$, there was a sharp increase in $\delta^{18} \mathrm{O}$ with two peaks in excess of $+3 \%$ lasting several decades, separated by an abrupt decrease to $+2 \%$, followed by a decline after $\mathrm{AD}$ 1600. Between $\mathrm{AD} 1600$ and $1720, \delta^{18} \mathrm{O}$ values remained low but variable. After AD 1720, sharp, decadal variations were superimposed on long-term increasing trend reaching a peak of almost $4 \%$ at c. AD 1810 . After AD $1810, \delta^{18} \mathrm{O}$ values remained high (averaging c. $3 \%$ ) but with bi-decadal oscillations of $\leq 1 \%$ amplitude.

[13] The mass-balance calculations for the lake suggest that a changing balance of inflow to evaporation, together with accompanying changes in relative humidity, could have caused the variations in $\delta^{18} \mathrm{O}$ from SG00C. This would imply a drying and then wetting trend, but with marked bidecadal variability, from $A D 1150$ to 1500 , reduced bidecadal variability from $\mathrm{AD} 1500$ to 1560 and then a rapid shift to very dry conditions between AD 1560 and 1600. A change to wetter conditions between AD 1600 and 1720 would have been followed by a trend to drier but more variable climate up until AD 1810 and continued dry climate since then, but with reduced variability. Under this interpretation, the part of the MWP represented in the record would have been relatively wet. Wet conditions would have continued into the LIA, but with episodes of aridity in the early LIA, and in the latter part of the LIA continuing to the present.

[14] Independent evidence for precipitation change over the past $\sim 850$ years and a test of the above interpretation of the $\mathrm{SG} 00 \mathrm{C} \delta^{18} \mathrm{O}$ values can be derived from the tree-ring record from Delingha [Shao et al., 2005] (Figure 2). Increased precipitation would be expected to accompany a shift to less positive $\delta^{18} \mathrm{O}$ values in the lake water, and hence the ostracode shells, whereas decreased precipitation coincides with the reverse. Precipitation change may also influence the lake's isotope balance indirectly, through its affect in relative humidity, as well as directly. Fluctuations in precipitation amount in the period AD 1150 to 1430 could potentially explain some of the changes in SG00C $\delta^{18} \mathrm{O}$ values over the same period. A prolonged interval of reduced precipitation from AD 1270 to 1310 coincides with a peak in $\delta^{18} \mathrm{O}$ in the Sugan Lake record. Similarly, a fall in $\delta^{18} \mathrm{O}$ values between $\mathrm{AD} 1310$ and 1330 was accompanied by an increase in precipitation. However, a marked dry phase from $\mathrm{AD} 1450$ to 1500 in the tree-ring record has no obvious parallel in the Sugan Lake $\delta^{18} \mathrm{O}$ values. Furthermore, the peak in $\delta^{18} \mathrm{O}$ values between $\mathrm{AD} 1560$ and 1600 was not accompanied by a reduction in precipitation although a later peak, from c. 1790 to 1820 , is. For the postAD 1820 period, $\delta^{18} \mathrm{O}$ values in SG00C remained relatively high, yet precipitation amount did not decline. Overall, although precipitation amount has had some control on the SG00C $\delta^{18} \mathrm{O}$ record, it cannot provide a complete explanation.

[15] Changes in temperature may also have affected the $\delta^{18} \mathrm{O}$ record from SG00C. A $1{ }^{\circ} \mathrm{C}$ rise in water temperature will cause a $\delta^{18} \mathrm{O}$ decrease of about $0.24 \%$ in calcite [Hays and Grossman, 1991] if other factors remain constant. A rise in temperature may also increase the meltwater input to the lake. Furthermore, mass balance calculations show that a rise in temperature will also cause a small decrease in the $\delta^{18} \mathrm{O}$ of lake water, through its effects on water - vapour fractionation, and this will have an additional control on the $\delta^{18} \mathrm{O}$ of ostracodes in the same direction as the thermodynamic effect on calcification and the influence of increased meltwater input. However, all of these influences may be offset by the rise in evaporative enrichment that would likely accompany increased temperature, such that changing water temperature probably had a relatively minor net effect on the SG00C $\delta^{18} \mathrm{O}$ record. This is supported by comparisons with tree-ring width time series from Sidalong [Liu et al., 2005] (Figure 2). Assuming that the variation in air temperature that this represents $\left(\leq 2^{\circ} \mathrm{C}\right)$ were translated into the same magnitude of change in water temperature, only about $0.5 \%$ of the change in $\delta^{18} \mathrm{O}$ of the ostracodes in SG00C could be attributed to temperature variation. However ring-width minima do correspond to some of the maxima in the $\delta^{18} \mathrm{O}$ record from SG00C, especially from AD 1270-1310 and around AD 1700 (Figure 2), suggesting that the increased fractionation between calcite and water $\left(\alpha_{\text {calcite-water }}\right)$ caused by lower water temperature may have contributed to these peaks, which also coincide with intervals of reduced precipitation.

[16] Changes in the isotopic composition of input water also influence the $\delta^{18} \mathrm{O}$ of lake water and hence ostracode 

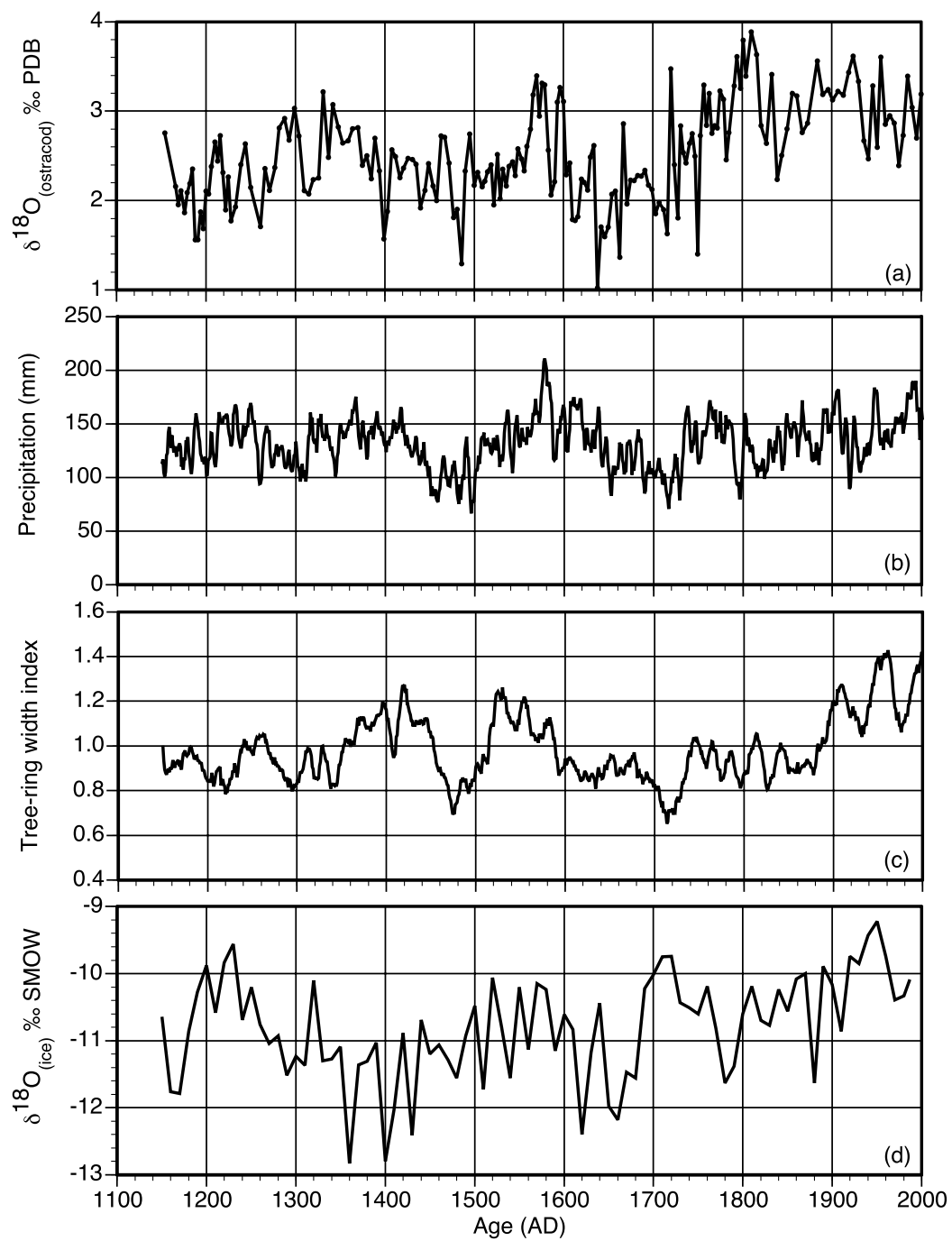

Figure 2. Climate variability over the northern Tibetan Plateau since $1150 \mathrm{AD}$ : (a) $\delta^{18} \mathrm{O}$ of ostracodes from Sugan Lake core SG00C, (b) precipitation reconstructed from tree rings at Delingha [Shao et al., 2005], and (c) standard tree-ring width chronology from Sidalong [Liu et al., 2005]. On the basis of a close correspondence between Tibetan Plateau temperature and the all-China reconstructions of Yang et al. [2002] for the past 1000 years, the total amplitude of ring-width change is estimated to represent temperature variation of $\leq 2^{\circ} \mathrm{C}$. (d) Decadally-averaged $\delta^{18} \mathrm{O}$ values from the Dunde ice core [Thompson et al., 1989].

shells. As discussed above, the steady-state isotope composition of Sugan Lake is sensitive to changes in the composition of the input water. The ice core from the Dunde ice cap, which lies at $5325 \mathrm{~m}$ a.s.l. and about $230 \mathrm{~km}$ southeast of Sugan Lake (Figure 1), provides a decadally-averaged record of oxygen-isotope variations in precipitation for the past millennium [Thompson et al., 1989] and, since it lies partly within Sugan Lake's catchment, is a good proxy for the oxygen-isotope composition of inflow water. Between $\mathrm{AD} 1150$ and 1260 , sharp variations in $\mathrm{SG} 00 \mathrm{C} \delta^{18} \mathrm{O}$ values were accompanied by changes in $\delta^{18} \mathrm{O}$ values in the ice core record $\left(\delta^{18} \mathrm{O}_{\text {Dunde }}\right)$, suggesting that variations in the isotopic composition of input water may have contributed to the variations in the lake-sediment core. Differences in timing of fluctuations in the two archives may reflect dating uncertainties. The peak in $\delta^{18} \mathrm{O}$ values in SG00C from AD 1280 to 1310 , however, has no corresponding changes in the ice core. From AD 1320 to 1560, both records once again display marked short-term variations. The peak in $\delta^{18} \mathrm{O}$ in SG00C from AD $1560-1600$ was accompanied by elevated $\delta^{18} \mathrm{O}$ values in the ice core record during an interval of increased precipitation and warmer temperature. The long-term rise and fall in $\delta^{18} \mathrm{O}_{\text {Dunde }}$ between AD 1660 and 1780 seems to have produced no comparable response in the SG00C record although the peak in $\delta^{18} \mathrm{O}$ values in the lake record does coincide with the peak in $\delta^{18} \mathrm{O}$ in the ice core. After $\mathrm{AD} 1800$, relatively high $\delta^{18} \mathrm{O}_{\text {Dunde }}$ values coincide with elevated values in SG00C.

[17] The large $\delta^{18} \mathrm{O}$ variations in Sugan Lake core SG00C in the latter part of the MWP seem to have been a complex function of changes in precipitation amount and in the $\delta^{18} \mathrm{O}$ values of input water $\left(\delta^{18} \mathrm{O}_{\mathrm{I}}\right)$, with a shift to drier conditions coupled with reduced $\delta^{18} \mathrm{O}_{\mathrm{I}}$ from $\mathrm{AD} 1270$ to 1300 . The earliest part of the LIA ( AD 1300-1340) was 
characterized by relatively wet conditions as indicated by low $\delta^{18} \mathrm{O}$ values in ostracodes in SG00C and confirmed by the tree-ring reconstructions. However, low $\delta^{18} \mathrm{O}_{\mathrm{I}}$ values may also have contributed to the SG00C signal. A period of elevated $\delta^{18} \mathrm{O}$ values in SG00C during the LIA, from AD $1790-1820$, occurred during a time of reduced precipitation in the tree-ring record and an increase in the $\delta^{18} \mathrm{O}_{\mathrm{I}}$ value. An earlier period of elevated $\delta^{18} \mathrm{O}$ values in $\mathrm{SG} 00 \mathrm{C}$, from $\mathrm{AD}$ $1560-1600$, is more difficult to explain since it appears to be accompanied by warmer and wetter, although variable, conditions with moderately high $\delta^{18} \mathrm{O}_{\mathrm{I}}$ value. Overall, the LIA was an interval of climatic complexity, with prominent dry periods separated by times of rather wetter climate. This finding supports previous observations from other terrestrial proxies for climatic variability during the LIA, as discussed above. The shift to higher $\delta^{18} \mathrm{O}$ values in SG00C post-AD 1700 is more difficult to explain, although the high average values for much of this period were accompanied by high average $\delta^{18} \mathrm{O}_{\mathrm{I}}$. Increased warming during the 20th century, which is seen over much of the Tibetan Plateau [Yang et al., 2002] and evident in the tree-ring record from Sidalong, may also have contributed to high $\delta^{18} \mathrm{O}$ values in SG00C by increasing evaporation and thereby reducing effective precipitation.

\section{Conclusions}

[18] Using independent evidence for changes in precipitation, temperature and the isotopic composition of input waters we have shown that variations in $\delta^{18} \mathrm{O}$ values in ostracode calcite from Sugan Lake are not solely a function of changing effective precipitation, the model often used to interpret oxygen-isotope records from lakes in arid to subhumid regions. Other controls, including temperature and the isotopic composition of input water, seem to have been important. In reality, none of these controls acts independently of the others. Rising temperature, for example, will often lead to an increase in the $\delta^{18} \mathrm{O}$ values of precipitation and will tend to increase the $\delta^{18} \mathrm{O}$ of lake water through greater evaporative enrichment. However, increased temperature will also lower the $\delta^{18} \mathrm{O}$ of carbonate precipitates because the fractionation of oxygen isotopes between calcite and water is inversely proportional to temperature. For Sugan Lake, we are fortunate in having independent records of the most important controls from nearby archives. Additional approaches to deconvolving a potentially complex carbonate isotope signal could involve alternative proxies for water temperature and water isotope composition, such as biomarkers [e.g., Liu et al., 2006]. However, at sites where independent evidence of temperature, precipitation, or input-water composition is unavailable, $\delta^{18} \mathrm{O}$ records from carbonates should be interpreted with care.

[19] Acknowledgments. We thank NSFC (projects 40301050, 40421101, and 40301051) and the Royal Society for funding, T. Atkinson and A. Osborn for help with stable isotope analyses, M. Davis and L. Thompson for ice-core data, X. Shao for tree-ring data, A. Zhou and J. Chen for assistance with the fieldwork, S. Mischke and an anonymous referee for perceptive reviews, and K. Zhang for ostracode picking.

\section{References}

Chen, F. H., X. Z. Huang, J. W. Zhang, J. A. Holmes, and J. H. Chen (2006), Humid Little Ice Age in and central Asia documented by Bosten Lake, Xinjiang, China, Sci. China, Ser. D, 49, 1280-1290.

Davis, M. E., L. G. Thompson, T. Yao, and N. Wang (2005), Forcing of the Asian monsoon on the Tibetan Plateau: Evidence from high-resolution ice core and tropical coral records, J. Geophys. Res., 110, D04101, doi:10.1029/2004JD004933.

Gonfiantini, R. (1986), Environmental isotopes in lake studies, in Handbook of Environmental Isotope Geochemistry: The Terrestrial Environment, edited by P. Fritz and J.-C. Fontes, pp. 113-168, Elsevier, New York.

Hays, P. D., and E. L. Grossman (1991), Oxygen isotopes in meteoric calcite cements as indicators of continental paleoclimate, Geology, 19, $441-444$.

Henderson, A. C. G. (2004), Late Holocene environmental change on the NE Tibetan Plateau: A palaeolimnological study of Lake Qinghai, China, based on stable isotopes, Ph.D. thesis, 222 pp., Univ. of London, London.

Hodell, D. A., J. H. Curtis, and M. Brenner (1995), Possible role of climate in the collapse of Classic Maya civilization, Nature, 375, 391-394.

Kebede, S., H. Lamb, R. Telford, M. Leng, and M. Umer (2002), Lakegroundwater relationships, oxygen isotope balance and climate sensitivity of the Bishoftu Crater Lakes, Ethiopia, in The East African Great Lakes: Limnology, Palaeolimnology and Biodiversity, edited by E. O. Odada and D. O. Olago, pp. 261-275, Springer, Dort, Netherlands.

Lister, G. S., K. Kelts, K. Z. Chen, Y. Jun-Qing, and F. Niessen (1991), Lake Qinghai, China: Closed-basin lake levels and the oxygen isotope record for ostracoda since the latest Pleistocene, Palaeogeogr. Palaeoclimatol. Palaeoecol., 84, 141-162.

Liu, X. H., D. H. Qin, X. M. Shao, T. Chen, and J. W. Ren (2005), Temperature variations recovered from tree-rings in the middle Qilian Mountain over the last millennium, Sci. China, Ser. D, 48, 521-529.

Liu, Z. H., A. C. G. Henderson, and Y. S. Huang (2006), Alkenone-based reconstruction of late-Holocene surface temperature and salinity changes in Lake Qinghai, China, Geophys. Res. Lett., 33, L09707, doi:10.1029/ 2006GL026151.

Majoube, M. (1971), Fractionnement en oxygène 18 et en deutérium entre l'eau et sa vapeur, J. Chim. Phys. Phys. Chim. Biol., 68, 1423-1436.

Shao, X. M., L. Huang, H. B. Liu, E. Y. Liang, X. Q. Fang, and L. L. Wang (2005), Reconstruction of precipitation variation from tree rings in recent 1000 years in Delingham, Qinghai, Sci. China, Ser. D, 48, 939-949.

Thompson, L. G., E. Mosley-Thompson, M. E. Davis, J. F. Bolzan, J. Dai, T. Yao, X. Wu, L. Klein, and Z. Xie (1989), Holocene-late Pleistocene climatic ice core records from Qinghai-Tibetan Plateau, Science, 246, 474-477.

Tian, L. D., T. D. Yao, A. Numaguti, and K. Q. Duan (2001), Relation between stable isotope in monsoon precipitation in southern Tibetan Plateau and moisture transport history, Sci. China, Ser. D, 44, 267-274.

Tian, L., T. Yao, P. F. Schuster, J. W. C. White, K. Ichiyanagi, E. Pendall, J. Pu, and W. Yu (2003), Oxygen-18 concentrations in recent precipitation and ice cores on the Tibetan Plateau, J. Geophys. Res., 108(D9), 4293, doi:10.1029/2002JD002173.

Wang, L. J., M. Sarnthein, H. Erlenkeuser, P. M. Grootes, J. O. Grimalt, C. Pelejero, and G. Linck (1999), Holocene variations in Asian monsoon moisture: A bidecadal sediment record from the South China Sea, Geophys. Res. Lett., 26, 2889-2892.

Wang, Y. J., H. Cheng, R. L. Edwards, Y. Q. He, X. G. Kong, Z. S. An, J. Y. Wu, M. J. Kelly, C. A. Dykoski, and X. D. Li (2005), The Holocene Asian monsoon: Links to solar changes and North Atlantic climate, Science, 308, 854-857

Yang, B., A. Braeuning, K. R. Johnson, and Y. F. Shi (2002), General characteristics of temperature variation in China during the last two millennia, Geophys. Res. Lett., 29(9), 1324, doi:10.1029/2001GL014485.

Zhou, A., F. Chen, M. Qiang, M. Yang, and J. Zhang (2007), The discovery of annually laminated sediments (varve) from Sugan Lake in inland arid China and their paleoclimate significance, Sci. China, Ser. D, 50, 12181224 .

F. Chen, M. Qiang, and J. Zhang, Center for Arid Environment and Paleoclimate Research (CAEP), MOE Key Laboratory of West China's Environmental System, Lanzhou University, Lanzhou, Gansu 730000, China.

J. A. Holmes, Environmental Change Research Centre, University College London, Gower Street, London WC1E 6BT, UK. (j.holmes@ucl. ac.uk) 